\title{
Spontaneous Atypical Intracerebral Hematoma in a Patient with Metastatic Colon Cancer using Bevacizumab without Central Nervous System Metastases
}

Hematoma intracerebral atípico espontâneo em um paciente com câncer de cólon
metastático em uso de Bevacizumabe sem metástases para o sistema nervoso central

Guilherme Gago da Silva', Antonio Dal Pizzol Junior², Alexei Peter dos Santos², João Pedro Einsfeld Britz $^{3}$, Paulo Valdeci Worm ${ }^{1}$

\begin{abstract}
We report a case of a patient with metastatic colon cancer without central nervous system metastases who presented with a spontaneous intraparenchymal hematoma using bevacizumab, without coagulation disorders or metastatic cells in the pathological examination. Bevacizumab is a monoclonal antibody against vascular endothelial growth factor (VEGF) that inhibits binding of the normal VEGF ligand to its receptor and is used to treat various tumors. Its therapeutic effect is believed to occur by limiting the formation of new blood vessels in tumors and decreasing their oxygenation. Fatal cerebrovascular events have been reported with the use of bevacizumab, raising the discussion of the safety of its use, especially in patients with brain metastases. At present, controversial remains as to bevacizumab increases the risk of cerebrovascular events.
\end{abstract}

Keywords: Bevacizumab; Cerebral hemorrhage; Neurosurgery; Intracranial hemorrhages; Antineoplastic agents.

\section{RESUMO}

Relatamos o caso de um paciente com câncer de cólon metastático sem metástases no sistema nervoso central que apresentou hematoma intraparenquimatoso espontâneo em uso de bevacizumabe, sem distúrbios de coagulação ou células metastáticas ao exame anatomopatológico. O bevacizumabe é um anticorpo monoclonal contra o fator de crescimento endotelial vascular (VEGF) que inibe a ligação VEGF ao seu receptor, sendo usado para tratar diversos tumores. Acredita-se que seu efeito terapêutico ocorra limitando a formação de novos vasos sanguíneos nos tumores e diminuindo sua oxigenação. Eventos cerebrovasculares fatais têm sido relatados com o uso de bevacizumabe, levantando a discussão sobre a segurança de seu uso, especialmente em pacientes com metástases cerebrais. No momento, permanece a controvérsia quanto ao bevacizumabe aumentar o risco de eventos cerebrovasculares.

Descritores: Bevacizumab; Hemorragia cerebral; Neurocirurgia; Hemorragias intracranianas; Agentes antineoplásicos.

1. São Jose Hospital, Santa Casa Hospital Complex, Department of Neurological Surgery - Porto Alegre - Rio Grande do Sul - Brazil.

2. Santa Rita Hospital, Santa Casa Hospital Complex, Department of Clinical Oncology - Porto Alegre - Rio Grande do Sul - Brazil.

3. University of Caxias do Sul, Medical school - Caxias do Sul - Rio Grande do Sul - Brazil.

Financial support: none to declare.

Conflicts of interest: The authors declare no conflict of interest relevant to this manuscript.

Correspondence author: João Pedro Einsfeld Britz.

E-mail: joaopedrobritz@hotmail.com / E-mail:JPEBritz@ucs.br 


\section{INTRODUCTION}

Bevacizumab (BVZ) is a monoclonal antibody targeting vascular endothelial growth factor (VEGF) first approved in the U.S., in 2004, for the treatment of metastatic colon cancer and rectal cancer. It is currently approved for several other cancers, including glioblastoma (GBM), triple negative metastatic breast cancer, renal cancer, ovarian cancer, cervical cancer, and non-small cell lung cancer (NSCLC), in addition to metastatic colorectal cancer. The therapeutic effect of BVZ is believed to occur by binding to VEGF, limiting the formation of new blood vessels in tumors, decreasing their vascular permeability, and thus reducing the oxygen supply to the tumor.

Overexpression of VEGF is observed in various types of tumors and is related to a worse patient prognosis. VEGF acts by binding and activating a receptor tyrosine kinase, which stimulates the growth of blood vessels. This mechanism plays a central role in the growth, invasion and metastasis of malignant tumors. Thus, BVZ can significantly increase overall and disease-free survival. Interruption of VEGF signaling is a major focus of new cancer therapy. ${ }^{[1-3]}$

Cerebrovascular events, such as hemorrhage, ischemia, and venous thrombosis, are the main concerns with the use of BVZ. A fatal cerebral hemorrhage was previously observed in a patient treated with $\mathrm{BVZ}_{i}^{[4]}$ thus, patients with brain metastases were routinely excluded from studies with BVZ. However, more recent data, showed that BVZ did not increase the risk of cerebral hemorrhage. ${ }^{[5,6]}$

The authors report the case of a patient with metastatic colon cancer using BVZ who presented two frontal lobe intracerebral hematomas, at the same time, raising the discussion of this possible complication. A review of published cases is discussed in this article.

\section{CASE REPORT}

A 79-years-old male on bevacizumab treatment due to metastatic colon cancer to liver, lung, and peritoneum, but no evidence of central nervous system involvement, developed aphasia, with no other changes in neurological examination. The patient had previously used xeloda (capecitabine) in combination with BVZ and had no previous hematological disorder. He was previously healthy, with no history of cardiovascular disease, and did not develop arterial hypertension during chemotherapy. The only previous comorbid was a degenerative cervical disc disease.

The patient underwent a brain tomography (CT) and magnetic resonance imaging (MRI) that identified large acute parenchymal hematoma located in the left frontal lobe with significant edema and mass effect, with signs of a $1.2 \mathrm{~cm}$ contralateral subfalcine herniation. Another acute parenchymal hematoma was located in the left frontal lobe (Figure 1). In addition to intraparenchymal hematomas, there were signs

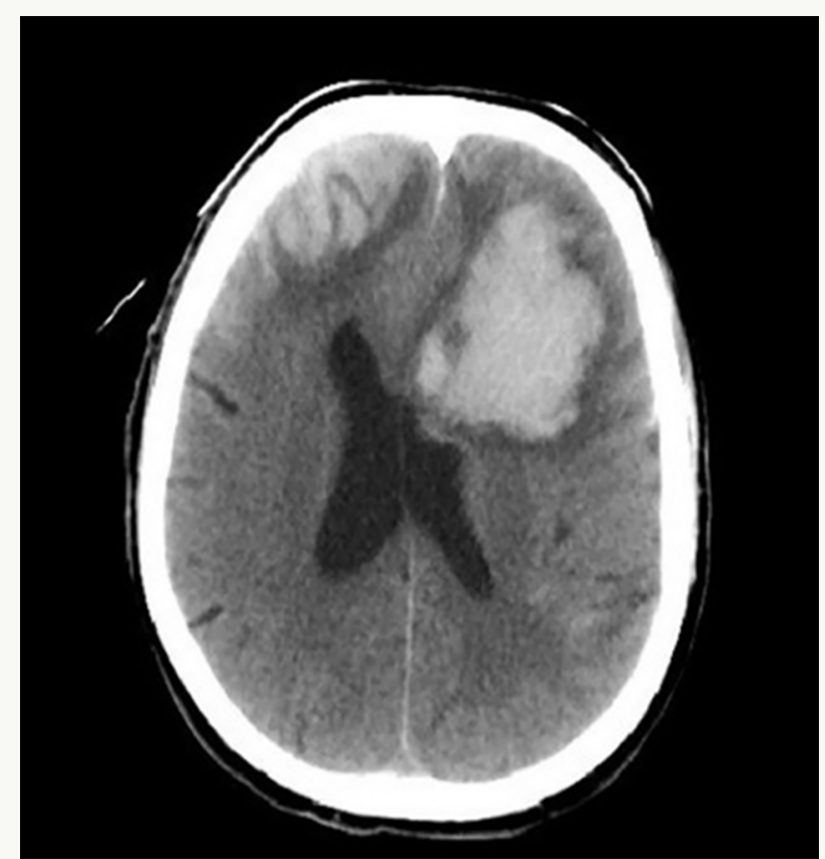

Figure 1. Acute parenchymal hematoma in the left frontal lobe

of ventricular hemorrhage and the presence of a laminar subdural hematoma in the right occipital region. Extensive residual deposits of hemosiderin on the leptomeningeal surface in the posterior fossa structures raised the possibility of superficial siderosis.

Measures to reduce edema and intracranial pressure were instituted. A single-time surgical resection was possible for both frontal lesions. The preoperative platelet count was 98,000 , and surgery was then performed to drain the hematoma and the material was sent for anatomopathological analysis. Postoperatively, the patient had improvement of the neurological deficit (Figure 2). The pathological examination showed only the presence of hematoma, without signs of metastatic cells. The patient died 1 month later due to respiratory infection.

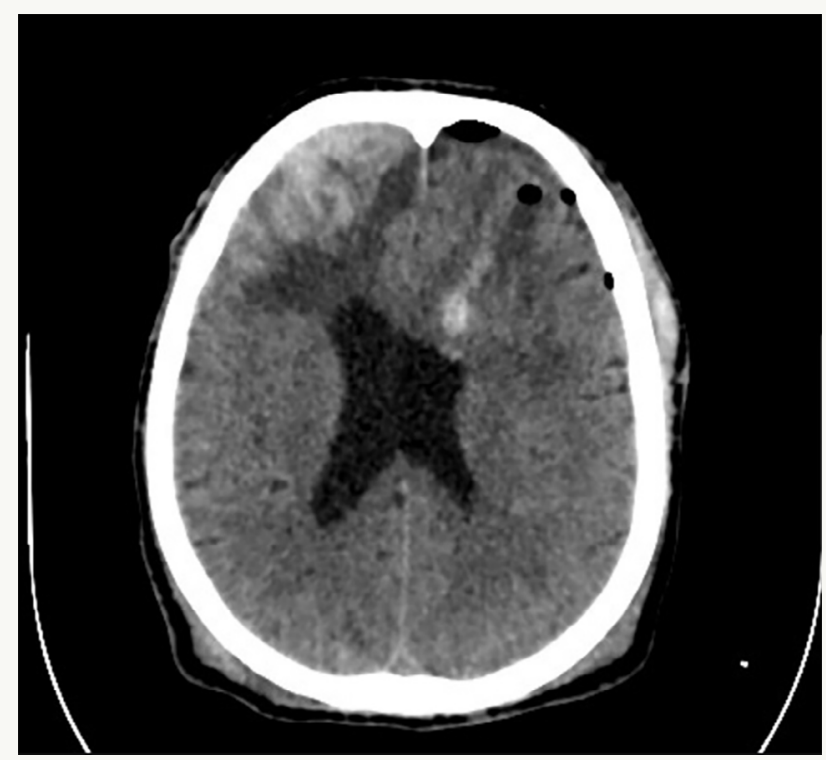

Figure 2 . Postoperative CT 


\section{DISCUSSION}

Nontraumatic (spontaneous) intracerebral hemorrhage (ICH) is the bleeding in the cerebral parenchyma that may or not extend to the ventricles and subarachnoid space. ICH accounts for $6.5 \%$ to $19.6 \%$ of stroke cases, and is associated with a higher mortality rate. Depending on the underlying cause, bleeding is classified as primary or secondary. Primary intracerebral hemorrhage originates from the spontaneous rupture of damaged small vessels and accounts for 78 to $88 \%$ of cases. Secondary hemorrhage is associated with vascular abnormalities or tumors. In patients with brain metastases, the risk of spontaneous bleeding varies greatly according to tumor histology, with significantly higher rates from melanoma and renal cell cancer metastases, compared to lung and breast metastases. ${ }^{[7-9]}$

Zuo et al. (2014) $)^{2}$ performed a literature review with meta-analysis to characterize the impact of BVZ on the occurrence of cerebrovascular events in cancer patients, and demonstrated that BVZ was associated with a threefold higher risk of both ischemic and hemorrhagic cerebrovascular events, and the risk was proportional to the BVZ dose. Of the 17 randomized controlled trials that were analyzed, 8 reported central nervous system (CNS) bleeding. This study also showed that the risk of cerebrovascular events varies by tumor type. Metastatic colorectal cancer, present in our case, is the tumor associated with the highest risk of bleeding with the use of $\mathrm{BVZ}$, a 6 times higher risk. ${ }^{[2]}$

Bevacizumab is also used to treat primary CNS tumors such as recurrent GBM and WHO grade III tumors following treatment with radiotherapy and temozolamide. Narita reviewed the efficacy and side effects of BVZ therapy for GBM and other brain tumors, and the most common side effect was hypertension, a known risk factor for vascular events such as ICH. ${ }^{10]}$ However, Yang et al. (2018), ${ }^{8}$ in another meta-analysis, found no significant difference in the risk of intracranial hemorrhage in patients treated with BVZ for solid tumors and brain metastases compared with those not received BVZ. Khasraw et al. (2012), 1 also reported that there was no difference in the incidence of $\mathrm{ICH}$ between patients with brain tumors who received BVZ and those who did not. Thus, BVZ does not appear to increase the incidence of $\mathrm{ICH}$ compared to the natural incidence of gliomas or brain metastases. ${ }^{[1,8]}$

It is supposed that several mechanisms may be involved in predisposition to cerebrovascular events after inhibition of VEGF signaling. VEGF promotes endothelial cell proliferation and stimulates their survival. Inhibition of VEGF could thus impair the regenerative capacity of the vessel wall, causing thrombosis or bleeding. VEGF also plays a role in vascular protection, with anti-apoptotic, anti-inflammatory, and cell pro-survival effects. Another mechanism involved is increased production of nitric oxide (NO) and prostacyclin by VEGF. Reduction of NO and prostacyclin may predispose to thromboembolic events. In addition, bevacizumab significantly increases the risk of hypertension in cancer patients. Sustained hypertension alters the architecture of blood vessels, making them more vulnerable to fluctuations in blood pressure, and contributing to CNS bleeding. ${ }^{[2,10,11]}$

In an analysis of 20 cases published in the literature, the frontal lobe was the most common bleeding site, totaling 8 cases, and in 7 cases there was more than one hematoma site. The patient's ages ranged from 29 to 81 years, and the most common type of primary cancer was NSCLC (6 cases), followed by colorectal cancer (4 cases), also present in our case. Four patients had GBM. Sarcoma, cancer of the rectum and fallopian tube were reported in one case each. As in our case, six patients were reported to have spontaneous $\mathrm{ICH}$, in the absence of brain metastases. The review of the published cases is summarized in Table 1.

Table 1. Review of published cases of ICH in patients using bevacizumab.

\begin{tabular}{lcccc}
\hline Author & Age & ICH location & Primary cancer & Metastasis or brain tumor \\
\hline Khasraw et al. $(2012)^{1}$ & $66 y$ & Parietal and frontal & Ovary & No \\
Khasraw et al. $(2012)^{1}$ & $73 y$ & Pontine & Ovary & No \\
Khasraw et al. $(2012)^{1}$ & $29 y$ & Extensive & Sarcoma & Yes \\
Khasraw et al. $(2012)^{1}$ & $44 y$ & Frontal & Colon & Yes \\
Khasraw et al. $(2012)^{1}$ & $58 y$ & Bifrontal & NSCLC & Yes \\
Khasraw et al. $(2012)^{1}$ & $66 y$ & Temporal and & GBM & Yes \\
Khasraw et al. $(2012)^{1}$ & $68 y$ & Frontotemporal & GBM & Yes \\
Khasraw et al. $(2012)^{1}$ & $57 y$ & Frontal and occipital & NSCLC & Yes \\
Khasraw et al. $(2012)^{1}$ & $70 y$ & Cerebellar & Ovary & No \\
Khasraw et al. $(2012)^{1}$ & $60 y$ & Frontal & GBM & Yes \\
Khasraw et al. $(2012)^{1}$ & $66 y$ & Frontal & NSCLC & Yes \\
Khasraw et al. $(2012)^{1}$ & $81 y$ & Temporal & GBM & Yes \\
Nishimura et al. $(2011)^{3}$ & $64 y$ & Multifocal & Rectum & No \\
Nishimura et al. (2011) & $65 y$ & Thalamus & Colon & No \\
Wang et al. $(2019)^{5}$ & $47 y$ & NR & NSCLC & Yes \\
Wang et al. $(2019)^{5}$ & $54 y$ & NR & NSCLC & Yes \\
Nguyen e Abrey (2007)12 & $72 y$ & Pontine & Fallopian tube & NR \\
Chen et al. $(2006)^{13}$ & NR & NR & Colorectal & NR \\
Giantonio et al. $(2007)^{14}$ & NR & NR & Colorectal & NR \\
Tanvetyanon et al. (2009) & $52 y$ & Vein draining to the SSS & NSCLC & NR \\
Our case & $79 y$ & Bifrontal & Colon & No \\
\hline
\end{tabular}

$y=$ Years old; NSCLC = Non-small cell lung cancer; GBM = Glioblastoma; NR = Not reported; SSS = Superior sagittal sinus. 
At present, controversy remains whether BVZ increases the risk of cerebrovascular events. Although not significantly different when compared to controls, several studies have reported a higher incidence of CNS ischemia or hemorrhage with the use of BVZ.

As BVZ is used extensively in routine cancer treatment and clinical trials, it is important to improve the diagnosis and management of the possible cerebrovascular side effects of bevacizumab. For patients receiving $B V Z$, physicians should be highly vigilant for any signs of cerebrovascular disorders. If a cerebrovascular event is detected, prompt assessment, and treatment are warranted.

\section{REFERENCES}

1. Khasraw M, Holodny A, Goldlust SA, DeAngelis LM. Intracranial hemorrhage in patients with cancer treated with bevacizumab: the Memorial Sloan-Kettering experience. Ann Oncol. 2012 Feb;23(2):458-63.

2. Zuo PY, Chen XL, Liu YW, Xiao CL, Liu CY. Increased risk of cerebrovascular events in patients with cancer treated with bevacizumab: a meta-analysis. PloS One. 2014 Jul;9(7):e102484.

3. Nishimura T, Furihata $M$, Kubo $H$, Tani M, Agawa $S$, Setoyama $\mathrm{R}$, et al. Intracranial hemorrhage in patients treated with bevacizumab: report of two cases. World J Gastroenterol. 2011 Oct;17(39):4440-4.

4. Gordon MS, Margolin K, Talpaz M, Sledge Junior GW, Holmgren E, Benjamin R, et al. Phase I safety and pharmacokinetic study of recombinant human anti-vascular endothelial growth factor in patients with advanced cancer. J Clin Oncol. 2001 Feb;19(3):843-50.

5. Wang Z, YangJ, Tu HY, Yan HH, Wu YL. Retrospective study on bevacizumab in the treatment of nonsmall cell lung cancer with brain metastases. Int J Clin Oncol. 2020 Feb;25(2):267-73.

6. Letarte N, Bressler LR, Villano JL. Bevacizumab and central nervous system (CNS) hemorrhage. Cancer Chem Pharmacol. 2013 Jun;71(6):1561-5.
7. Qureshi Al, Tuhrim S, Broderick JP, Batjer $\mathrm{HH}$, Hondo $\mathrm{H}$, Hanley DF. Spontaneous intracerebral hemorrhage. N Engl J Med. 2001 May;344(19):1450-60.

8. Yang L, Chen CJ, Guo XL, Wu XC, Lv BJ, Wang HL, et al. Bevacizumab and risk of intracranial hemorrhage in patients with brain metastases: a meta-analysis. J Neurooncol. 2018 Mar;137(1):49-56.

9. Gross BA, Jankowitz BT, Friedlander RM. Cerebral intraparenchymal hemorrhage: a review. JAMA. 2019 Apr;321(13):1295-303.

10. Narita Y. Drug review: safety and efficacy of bevacizumab for glioblastoma and other brain tumors. Jpn J Clin Oncol. 2013 Jun;43(6):587-95.

11. Kamba T, McDonald DM. Mechanisms of adverse effects of anti-VEGF therapy for cancer. $\mathrm{Br} J$ Cancer. 2007 Jun;96(12):1788-95.

12. Nguyen TD, Abrey LE. Intracranial hemorrhage in patients treated with bevacizumab and lowmolecular weight heparin. Clin Adv Hematol Oncol. 2007 May;5(5):375-6; discussion:337-9.

13. Chen HX, Mooney M, Boron M, Vena D, Mosby $\mathrm{K}$, Grochow L, et al. Phase II multicenter trial of bevacizumab plus fluorouracil and leucovorin in patients with advanced refractory colorectal cancer: an NCl Treatment Referral Center Trial TRC-0301. J Clin Oncol. 2006 Jul;24(21):3354-60.

14. Giantonio BJ, Catalano PJ, Meropol NJ, O'Dwyer PJ, Mitchell EP, Alberts SR, et al. Bevacizumab in combination with oxaliplatin, fluorouracil, and leucovorin (FOLFOX4) for previously treated metastatic colorectal cancer: results from the Eastern Cooperative Oncology Group Study E3200. J Clin Oncol. 2007 Apr;25(12):1539-44.

15. Tanvetyanon T, Murtagh R, Bepler G. Rupture of a cerebral arteriovenous malformation in a patient treated with bevacizumab. J Thorac Oncol. 2009 Feb;4(2):268-9. 